\title{
A Go/No-go approach to uncovering implicit attitudes towards safe and risky driving
}

\author{
Martinussen, Laila Marianne; Sømhovd, Mikael J.; Møller, Mette; Siebler, Frank
}

Published in:

Transportation Research. Part F: Traffic Psychology and Behaviour

Link to article, DOI:

10.1016/j.trf.2015.02.005

Publication date:

2015

Document Version

Peer reviewed version

Link back to DTU Orbit

Citation (APA):

Martinussen, L. M., Sømhovd, M. J., Møller, M., \& Siebler, F. (2015). A Go/No-go approach to uncovering implicit attitudes towards safe and risky driving. Transportation Research. Part F: Traffic Psychology and Behaviour, 30, 74-83. https://doi.org/10.1016/j.trf.2015.02.005

\section{General rights}

Copyright and moral rights for the publications made accessible in the public portal are retained by the authors and/or other copyright owners and it is a condition of accessing publications that users recognise and abide by the legal requirements associated with these rights.

- Users may download and print one copy of any publication from the public portal for the purpose of private study or research.

- You may not further distribute the material or use it for any profit-making activity or commercial gain

- You may freely distribute the URL identifying the publication in the public portal 
A Go/No-go approach to uncovering implicit attitudes towards safe and risky driving

Laila M. Martinussen $^{* a}$, Mikael J. Sømhovd ${ }^{b}$, Mette Møller ${ }^{\mathrm{a}}$, Frank Siebler ${ }^{\mathrm{c}}$

${ }^{a}$ DTU Transport, Bygningstorvet 116b, DK-2800 Kgs, Lyngby, Denmark

${ }^{\mathrm{b}}$ Department of Psychology, Copenhagen University, Øster Farimagsgade 2A, 1353

København K, Denmark

${ }^{\mathrm{c} D e p a r t m e n t ~ o f ~ P s y c h o l o g y, ~ U n i v e r s i t y ~ o f ~ T r o m s ø, ~ H u g i n b a k k e n ~ 32, ~} 9037$ Tromsø, Norway

*Corresponding author. Tel. +45 452565 00; fax: +45 45936533

E-mail address: laima@transport.dtu.dk (L. M. Martinussen) 


\begin{abstract}
Self-report measures of driving-related attitudes and beliefs miss potentially important precursors of driving behavior, namely, automatic and implicit thought processes. The present study used an adapted Go/No-go Association Task to measure implicit thought without relying on the participants' self-reports. Implicit attitudes towards safe and risky driving were measured in 53 Danish drivers ( 31 female, 22 male). Further, we explored the relationship between implicit attitudes towards risky and safe driving, and self-reported driving behavior and skills. The results suggest that implicit attitudes towards driving behavior can be measured reliably with the Go/No-go Association Task. Also, the results suggest that implicit attitudes towards safe driving and risky driving, respectively, may be separable constructs, and might thus stem from different cognitive processes. Finally, implicit attitudes were significantly related to self-reported driving behavior and skills for male (but not female) drivers. Pending future research with larger sample sizes, the difference between implicit attitudes towards safe versus risky driving that we observed may contribute to a greater theoretical understanding of the causes of safe and risky driving.
\end{abstract}

Keywords: Implicit attitudes, Safe driving, Risky driving, Driving behavior, DBQ, DSI 


\section{Introduction}

The relationship between attitude and behavior has been subject to considerable debate. However, a meta-analysis by Kraus (1995) showed that attitudes generally predict self-reported behavior. This is also the case in the area of road safety, where a number of studies have identified a relationship between attitudes and self-reported driving behavior (e.g. Armitage, Norman, \& Conner, 2002; Chan, Wu, \& Hung, 2010; Iversen, 2004; Marcil, Bergeron, \& Audet, 2001; Parker, Manstead, \& Stradling, 1992; Parker, Manstead, Stradling, Reason, \& Baxter, 1992; Parker, Lajunen, \& Stradling, 1998). Consequently, changing the attitude towards the target behavior is often seen as a key element in preventive strategies. However, as stated by Ulleberg and Rundmo (2003), a very limited effect of this approach has been found. The limited effect may be caused by many factors, and therefore a better understanding of the relationship between attitude and road user behavior is needed.

When exploring driving behavior and attitudes, researchers mostly apply self-report measures. Therefore, the current knowledge about the relationship between attitudes and behavior in relation to road safety is mainly based on consciously accessible attitudes. However, it has been suggested that in order to get a more detailed understanding of the psychological processes behind this relationship, it is important to look into both the explicit, deliberate processes (i.e., how drivers' conscious attitudes influence behavior) and the implicit processes (i.e., how drivers' unconscious or automatic attitudes influence behavior) (Sibley \& Harré, 2009b). Thus, a more comprehensive understanding of driving behavior and attitudes can be obtained by studying both explicit and implicit processes.

\subsection{Implicit cognition and driving behavior}

Implicit attitudes reflect "introspectively unidentified (or inaccurately identified) traces of past experience” (Greenwald \& Banaji, 1995, p. 5). Whereas self-report measures of preferences or evaluations reveal a participant's introspectively accessible explicit attitude, the measurement of implicit attitudes requires indirect methods that do not rely on a participant's introspection. Implicit attitudes are frequently measured from response errors or from the speed of responding in simple computer tasks that do not require consciously accessing one's attitudes (see below for further details). Measures of implicit attitudes are different from measures that merely encourage fast or spontaneous responding such as, for example, the Response-Frequency Measure of Habit (Aarts, Verplanken, \& van Knippenberg, 1997; Verplanken, Aarts, van Knippenberg, \& Moonen, 1998; Verplanken, Aarts, van Knippenberg, \& van Knippenberg, 1994). The latter instruments still require brief 
conscious introspection related to the attitude under investigation before a response can be given. Measures of implicit attitudes, in contrast, are designed to eliminate the need for introspection about the measured attitude completely.

Several studies have shown that implicit attitudes can be activated automatically and can direct behavior without conscious awareness (Chen \& Bargh, 1999; Dovidio, Kawakami, Johnson, Johnson, \& Howard, 1997; see also Greenwald \& Banaji, 1995). The differences between explicit attitudes and implicit attitudes, and the effect of the two on behavior, have been studied within many fields of psychology, including social and cognitive psychology (Fazio \& Olson, 2003; Swanson, Rudman, \& Greenwald, 2001), clinical psychology (Buhlmann, Teachman, \& Kathmann, 2011; Knowles \& Townsend, 2012; Teachman, 2007; Teachman, Gregg, \& Woody, 2001), developmental psychology (Baron \& Banaji, 2006; Dunham, Baron, \& Banaji, 2004; Phelps, O’Connor, Cunningham, Funayama, Gatenby, Gore, et al., 2000), market research (Maison, Greenwald, \& Bruin, 2001), and health psychology (Teachman, Gapinski, Brownell, Rawlins, \& Jeyaram, 2003). Recently, also traffic psychology added to the array (Harré \& Sibley, 2007; Hatfield, Fernandes, Faunce, \& Job, 2008; Sibley \& Harré, 2009a, b). The relationship between explicit attitudes, implicit attitudes, and behavior varies by context. However, implicit attitudes appear predictive of fast or spontaneous decision making, whereas explicit attitudes are more predictive of deliberate behavior (Perugini, 2005; Rydell \& McConnell, 2006).

An advantage of assessing implicit attitudes, compared to explicit attitudes, is that the responses are less prone to self-presentation strategies. This methodological feature is valuable as implicit measures are less biased by participants' motivation to respond in a desirable way. Therefore measures of implicit attitudes supplement measures of self-report in a relevant way.

Despite the relevance, research assessing implicit attitudes in traffic psychology is scarce. To our knowledge few studies have been conducted. Implicit attitudes towards speeding were assessed by Hatfield et al. (2008) who demonstrated negative evaluation of speeding not only in explicit attitudes, but also in implicit attitudes. Sibley and Harré (2009a) tested the impact of different traffic safety advertisements on drivers' explicit and implicit self-enhancement bias (excessive belief in own driving skills) and found that only explicit attitudes were affected by the advertisements. In another study, drivers' self-enhancement bias in relation to driving ability and driver caution was tested (Harré \& Sibley, 2007). It was found that especially men displayed a strong self-enhancement bias in driving ability, and that both men and women had strong self-enhancement bias in driver caution. Further, the effect 
was stronger when measured implicitly rather than explicitly. Finally is has been found that men had significantly higher levels of driving self-enhancement bias than women, both explicitly and implicitly (Sibley \& Harré, 2009b).

\subsection{The IAT and the Go/No-go Association task}

The previous studies within traffic psychology that measured implicit attitudes applied the Implicit Association Test (IAT) method. The IAT (Greenwald, McGhee, \& Schwartz, 1998) measures the mental association between concepts from reaction times, bypassing deliberate processing. The assumption behind it is that it is easier for people to respond when concepts are strongly connected in the mind (Nosek \& Banaji, 2001; Nosek, Greenwald, \& Banaji, 2007). The IAT is designed to test the preference for one of two oppositely valued target concepts, or pairs of attitude objects. The classic example is insects versus flowers. In the traffic safety context, this could be replaced with risky versus safe driving behavior. However, having a positive attitude towards one concept, does not necessarily imply that one has a negative attitude towards the opposite concept. For example, having a positive attitude towards talking on the mobile phone while driving, does not imply that one has a negative attitude towards not talking on the phone while driving. Further, there might not always exist a saliently opposite concept to the concept under investigation (for further discussion of this methodological problem of the IAT see $\mathrm{f}$. ex. Brendl, Markman, \& Messner, 2001; Nosek \& Banaji, 2001; Siebler, González, Ordóñez, Bohner, Haye, Sirlopú, et al., 2010).

Previous research on implicit attitudes in the traffic safety context has used the IAT. However, target concepts such as safety and risk may not be opposite pairs in people’s minds, but may be empirically separable constructs. To investigate this possibility, research instruments are needed that allow for the measurement of implicit attitudes towards the concepts separately. Fortunately such instruments exist.

One measure of implicit attitudes that does not rely on opposing concepts is the Go/No-go Association task (GNAT) method (Nosek \& Banaji, 2001). The GNAT allows the researcher to test implicit attitudes towards single attitude concepts like for example insects, without the comparison with flowers. In a traffic safety context, this gives the opportunity to test implicit attitudes towards risk and safety separately. Unlike the IAT, the GNAT has not yet been extensively applied, and thus more studies are of methodological interest. The GNAT will be described in more detail in the materials and method section. 


\subsection{Self-reported driving behavior and driving skills}

The primary purpose of the present study was to explore implicit attitudes towards safe and risky driving. A second purpose was to compare these attitudes to self-reported driving behavior as measured by the Driver Behavior Questionnaire (DBQ) (Reason, Manstead, Stradling, Baxter, \& Campbell, 1990), and to driving skills as measured by the Driving Skill Inventory (DSI) (Lajunen \& Summala, 1995).

Because driving behavior generally refers to the way persons prefer to drive or habitually drive the car, and driving skills refer to how good drivers are at handling the car (Elander, West, \& French, 1993; Evans, 1991; Näätänen \& Summala, 1976), the two are interrelated in expressing a general way of driving, and both have been related to self-reported accident involvement (de Winter \& Dodou, 2010; Glendon, 2007; Lajunen, Corry, Summala, \& Hartley, 1998a; Lawton, Parker, Manstead, \& Stradling, 1997; Parker, Reason, Manstead, \& Stradling, 1995a; Parker, West, Stradling, \& Manstead, 1995b; Rimmö \& Åberg, 1999). Thus, driving skills and behavior are related to how safe or risky drivers are in traffic, and therefore we wanted to compare these explicit measures of driving behavior to the implicit attitudes.

In the DSI, driving skills are divided into two types of skills, perceptual-motor skills and safety skills. Perceptual-motor skills rely on information-processing and motor skills, whereas safety skills rely on attitudes and personality factors (Lajunen \& Summala, 1995). High levels of perceptual-motor skills have been found to be related to risky driving behavior such as driver aggression and accident involvement, whereas the opposite has been found for high levels of safety skills (Lajunen et al., 1998a; Lajunen, Parker, \& Summala, 1998b; Lajunen \& Summala, 1995, 1997; Sümer, Özkan, \& Lajunen, 2006).

In the DBQ, driving behaviors are divided into violations, errors, and lapses (Reason et al., 1990). Violations are intentional "bad” driving behavior such as aggressive driving; errors are intentional behavior that does not achieve the intended outcome, such failing to notice pedestrians crossing; and lapses are unintentional driving behavior such as getting into the wrong lane (Reason et al., 1990). Because violations mostly are intentional acts, safety skills can be regarded as the motivation not to perform violations. This has been supported by previous studies, which have highlighted that attitudes towards safety can be a mediator for aggressive driving behavior (Lajunen et al., 1998b). Because lapses are considered less dangerous and have less impact on traffic safety (Parker et al., 1995a), only violations and errors were used as measures of driving behavior in the present study. 


\subsection{The present study}

The present study's aims were firstly, to test whether the GNAT is a reliable measure of implicit attitudes towards risky and safe driving; second, whether implicit attitudes towards risky driving vs. towards safe driving are separable constructs; and thirdly, to compare drivers' implicit attitudes towards risky and safe driving with their self-reported driving behavior and skill.

We expected the GNAT to be a reliable measure. We had no predictions about the separability of implicit attitudes towards safe and risky driving; the study merely explored this possibility. We expected to find a relationship between implicit attitudes to safe driving and risky driving, and self-reported driving behavior. Similarly, we expected to find a relationship between implicit attitudes to safety and risk, and self-reported driving skills.

\section{Materials and methods}

\subsection{Participants and procedure}

As can be seen in Table 1, the study included 53 drivers. All participants had minimum type B driver license for personal car. All participants had completed the DBQ and the DSI in a previous study (see Martinussen, Møller, \& Prato, 2014), and were invited by email to take part in an online study with a purpose-built GNAT.

Insert Table 1 about here

\subsection{Assessment of implicit attitudes using the GNAT}

Overview. The GNAT procedure (see below for details) requires participants to perform a simple, non-evaluative classification task with stimuli that represent a target category (f. ex. the category "risky driving”). The task is to be done several times, in systematically varying contexts: sometimes the context is evaluatively positive; at other times it is evaluatively negative. The implicit attitude towards the category is computed from the difference in task performance between the two contexts. For example, if performance in the category-related task is greater when the context is negative rather than positive, then that is interpreted as a negative implicit attitude towards the target category.

Stimulus materials. The present study measured implicit attitudes towards two target categories: safe driving, and risky driving. These were represented by pictures of safe and risky driving situations (see Figure 1 for an example). Evaluative contexts were created with positive and negative words (f. ex., positive: “smile,” “pleasure;” negative: 
“evil,” “catastrophe;” see Appendix A for a complete list). The pictures and words were chosen from a pilot-study $(N=80)$ where pictures of risky and safe driving situations had been rated on five-point semantic differential scales anchored in (0) not dangerous and (4) very dangerous; positive and negative words had been rated on fivepoint semantic differential scales anchored in (-2) very negative and (2) very positive.

GNAT procedure. The GNAT presented stimuli for a short time on the computer screen, one stimulus at a time. The participants were asked to press a response button (the "go" response) if the stimulus on the screen belonged to either a given target category (e.g., it was a picture of a risky driving situation) or a given attribute dimension (e.g., it was a negative word). If the stimulus did not belong to either of these, the participants were asked to do nothing (the "no-go" response). Figure 1 illustrates one such trial: as indicated by the labels "Risky" and "Negative" at the top of the display, a key-press is to be made if either a risky driving situation or a negative word is shown in the center of the screen; otherwise no key-press is to be made. Because the display in Figure 1 does in fact show a risky driving situation, the correct response in this example is to press the key. The participants were given a short temporal window to respond; if the key was not pressed during this interval, the computer registered a "no-go" response and proceeded automatically. The registered "go" and "no-go” responses were afterwards converted into scores that reflected whether the response was correct or wrong.

Repeated GNAT measures. We presented the full set of stimuli repeatedly, in blocks of 74 trials each that differed in their instructions. To enable the subsequent computation of implicit attitude scores towards safe driving, one block required the "go" response if the stimulus was a picture of a safe driving situation or if it was a positive word ("safe+positive"), whereas another block required the "go" response if the stimulus was the picture of a safe driving situation or if it was a negative word ("safe+negative"). Analogously, the subsequent computation of implicit attitudes towards risky driving was enabled by including “risky+positive” and "risky+negative” blocks. Further, one of our research questions concerned the reliability of GNAT scores. Therefore all blocks were presented twice, which enabled the subsequent computation of two independent implicitattitude scores per participant for each target category. In line with the GNAT literature we collected the two independent measures under different response deadlines (750 and 600 milliseconds, respectively). This procedural variation works against finding good reliability and is therefore considered a particularly conservative strategy (for further discussion see Nosek and Banaji, 2001). 
Scoring. In a first step we computed indices of task performance for each trial block. As is usual in the GNAT literature we adopted sensitivity scores (signal-detection $d$ ') as our performance measure; greater scores indicate better performance. Different from simpler performance measures such as the proportion of correct responses, sensitivity scores are less prone to strategic responding (see Nosek and Banaji, 2001, for further detail). From the block-wise performance indices we then derived implicit attitude scores for each target category (safe driving, risky driving) by computing the difference in performance between associated blocks. For convenience of interpretation, the direction of computing the difference ("safe+positive" minus "safe+negative;" "risky+negative” minus "risky+positive”) was chosen such that greater difference scores consistently represent more normatively desirable implicit attitudes (pro-safety; anti-risk). Separate scores were computed within each response deadline condition. Overall then, the scoring procedure yielded four independent GNAT scores per participant; these represented implicit attitudes towards two target categories (safe driving, and risky driving), as measured under two response deadlines each (750ms, and 600ms). For the two measures of implicit attitudes towards safe driving, greater scores indicate stronger pro-safety attitudes, whereas for the two measures of implicit attitudes towards risky driving, greater scores indicate stronger anti-risk attitudes.

Insert Fig. 1 about here

\subsection{Assessment of driving behavior and driving skills using the DBQ and the DSI}

We included two explicit measures of driving behavior and skills in the study: the Driver Behavior Questionnaire (DBQ; Reason et al., 1990) and the Driving Skill Inventory (DSI; Lajunen \& Summala, 1995).

The DBQ. Across different driving behaviors, the Driver Behavior Questionnaire assesses how frequently respondents have performed violations, errors, and lapses, using a six-point Likert scale anchored in Never and Nearly all the time (for a detailed description see Martinussen, Hakamies-Blomqvist, Møller, Özkan \& Lajunen, 2013; Reason et al., 1990). The sum scores of violations and errors were averaged into a single index where greater scores indicate a greater number of self-reported violations and errors.

The DSI. Across different driving situations, the Driving Skill Inventory assesses how good respondents consider their own perceptual-motor skills and safety skills to be, using a five-point Likert scale anchored in Well below average and Well above average (for 
a detailed description see Lajunen \& Summala, 1995). Safety skills and perceptual-motor skills were averaged into a single index where greater scores indicate greater self-reported perceptual-motor and safety skills.

\section{Results}

\subsection{Inter-correlations between implicit attitudes towards risky and safe driving}

As can be seen in Table 2, across the two response deadlines, implicit attitudes towards the same attitude concept (risk600 vs. risk750; safe600 vs. safe750) correlated positively and significantly. This holds true both for implicit attitudes towards safe driving $(r=.40, p<.01)$ and for implicit attitudes towards risky driving $(r=.45, p<$ .01). These findings indicate that GNAT measures of the same attitude concepts lead to repeatable results, even across different response deadlines. Thus, our results suggest that implicit attitudes in the traffic domain can be measured reliably with the GNAT. At the same time, within each response deadline, the correlations between implicit attitudes towards different attitude concepts (safe750 vs. risk750; safe600 vs. risk600) were weaker and non-significant for both the 750ms threshold $(r=.27, p>.05)$ and the $600 \mathrm{~ms}$ threshold ( $r=.27, p>.05$ ). These findings provide initial empirical evidence that implicit attitudes towards risky driving and safe driving may be empirically separable constructs rather than the poles of a single underlying dimension.

\section{Insert Table 2 about here}

\subsection{Implicit attitudes and self-reported driving behavior}

As has just been described, implicit attitude scores towards the same attitude concept (but measured under different response deadlines) were significantly correlated. Therefore we averaged the GNAT scores across response deadlines for the next analyses. The mean and standard deviation of the implicit attitudes scores, and their correlations with the DBQ and DSI scores, can be seen in Table 3. For the whole sample, implicit attitudes towards risk correlated marginally significantly with the DBQ scores. For the women, none of the correlation coefficients were statistically significant. In contrast, we observed two significant correlations for the men. Men’s DBQ scores and implicit attitudes towards risky driving correlated positively and significantly, suggesting a counterintuitive result, namely that a greater number of self-reported traffic violations and errors was associated with stronger implicit anti-risk attitudes, $r=.44, p<.05$. We will return to this finding in the Discussion. 
A follow-up analysis revealed that the correlation was due to the DBQ sub-score "violations" $\left(r_{\text {violations }}=.49, p<.05\right)$, but not to the sub-score "errors" $\left(r_{\text {errors }}=.12\right.$, n.s. $)$. This pattern suggests that driving errors as measured by the DBQ may be genuine errors rather than the result of implicit thought processes. Further, men’s DSI scores and implicit attitudes towards safe driving correlated negatively and significantly, suggesting that lower self-reported driving skills were associated with stronger implicit pro-safety attitudes, $r=-.63, p<.01$. A follow-up analysis revealed that the correlation was due to both of the DSI sub-scores to approximately the same degree $\left(r_{\text {perceptual-motor skills }}=-.58, p<.01 ; r_{\text {safety skills }}=-.53, p<.02\right)$.

\section{Insert Table 3 about here}

\section{Discussion}

The current study is, to the authors' knowledge, the first study to test implicit attitudes towards risky and safe driving by the use of the GNAT. The pattern of intercorrelations between four independent GNAT scores suggests that implicit driving-related attitudes can be measured reliably with the GNAT, and further, that implicit attitudes towards risky driving and safe driving may be distinct constructs. The results also revealed interesting differential correlations of the two implicit-attitude scores with the explicit measures, the DBQ and the DSI, thereby again supporting the notion that implicit attitudes towards safe driving and risky driving may be separable constructs. However, these correlations were found in relation to the male participants only.

\subsection{Reliability and validity of the GNAT}

Two response deadlines each (600ms, $750 \mathrm{~ms})$ were used to measure implicit attitudes towards safe driving and risky driving. The inter-correlations between the resulting four GNAT scores show that the instrument reveals similar implicit attitudes towards the same attitude concept, independent of the particular response deadline used, which indicates reliability of the research instrument. Within each response deadline, implicit attitudes towards different (though related) attitude concepts were found to correlate moderately, with the expected positive sign. The observation that the attitude scores correlated positively may be interpreted as first evidence for our GNAT’s convergent validity: when measuring attitudes towards related concepts, the instrument reveals related attitudes. At the same time, the positive correlation of implicit attitudes towards safe and risky driving was only of moderate magnitude and non-significant, indicating that the GNAT is sensitive enough to 
capture differences in the two attitudes.

\subsection{Implicit attitudes, the DBQ and the DSI}

\subsubsection{Gender difference}

Our results showed gender differences in the correlation pattern between implicit attitudes and the DBQ and DSI scores (see Table 3). Various authors suggest that implicit attitudes may be more predictive of spontaneous decision making, whereas explicit attitudes may be more predictive of deliberate behavior (f. ex., Perugini, 2005; Rydell \& McConnell, 2006). If so, then one reason for the gender difference may be that driving behavior is less spontaneous among women than among men. Support for this view stems from studies showing that men have more symbolic and affective motives for car use than women (Ellaway, Macintyre, Hiscock, \& Kearns, 2003; Lois \& López-Sáez, 2009; Steg, 2005). Similarly, prior studies have also found gender differences in the effects of implicit and explicit cognition in relation to driving. It has been shown that men explicitly report greater gender-stereotypical "macho" driving attitudes than women (Harré, Field, \& Kirkwood, 1996), and that such attitudes are linked to greater driving aggression (Krahé \& Fenske, 2002). Also, previous studies have shown that the number of violations increased as a function of masculinity, whereas high levels of femininity reduced these effects (Özkan \& Lajunen, 2005). Moreover, Harré and Sibley (2007) and Sibley and Harré (2009b) found stronger evidence of self-enhancement, measured explicitly as well as implicitly, in men than in women. This indicates that the link between masculine role identification and selfenhancement of driving ability are not only produced by reasoned beliefs of how one should act, but is expressed also at an unconscious level (Sibley \& Harré, 2009b). From this prior research, we might expect that driving has a different meaning to men than women, both because of gender role identification and because of the greater affective and symbolic motives related to driving for men. A link between implicit cognitive processes and selfreported driving behavior should therefore be particularly pronounced, and consequently more readily detectable, in men than in women.

\subsubsection{Implicit attitudes towards risky driving, and aberrant driving behavior}

Counterintuitively, our findings show that the more own traffic violations drivers report, the more negative implicit attitude towards risky driving they possess. Intuitively one would expect drivers to possess a positive attitude towards risky driving if they engage in such behavior. An explanation for the result may again stem from macho gender role 
identification.

Our society promotes safe driving through media, driver training and information campaigns (Delhomme, Grenier, \& Kreel, 2008), and most drivers are aware of the dangers of risky driving. However, such knowledge may be overridden by gender role ideals, leading to driver aggression (Harré et al., 1996; Krahé \& Fenske, 2002). This mechanism might lead male drivers to engage in aberrant driving. Anti-risk attitudes might result from drivers learning from the effect of own reckless driving behavior. Hypothetically, to the degree that the own past violations had unpleasant consequences, these drivers may have "learned their lesson” - which is to dislike risk. However, in the continued presence of macho gender roles, this implicit dislike might not be sufficient to change behavior. Another possible explanation might be that male drivers with implicit anti-risk attitudes simply are better at detecting risky driving as risky, and thus more likely to recognize their own traffic violations, and also to remember (and report) them. The exact mechanisms that relate negative implicit riskattitudes to riskier driving behavior cannot be identified from the present data but provide an interesting avenue for future research.

\subsubsection{Implicit attitudes towards safe driving, and driving skills}

Our study shows that men reporting low driving skills may hold a pro-safety attitude. Quasi as a mirror-image of the finding described above, this may again stem from differences in self-exposure to certain kinds of driving situations. Several studies suggest that drivers who rate their own driving skills as high also perceive a lesser risk for accidents (DeJoy, 1989; Harré, Foster, \& O’Neill, 2005; Harré \& Sibley, 2007; Lajunen \& Summala, 1995; Näätänen \& Summala, 1976). Conversely, drivers who rate their own driving skills and abilities as low should then value safety more, consequently leading them to systematically adopt safe driving techniques. If so, then the low-skill drivers will see the consequences of various driving behaviors differently often in daily life: frequently for safe driving (which they often engage in), but less frequently for risky driving (which they rarely engage in, if at all). Frequent good experiences with safe driving may then lead to strong implicit pro-safety attitudes, whereas the infrequent firsthand experience with risky driving may be insufficient to develop detectable implicit risky-driving attitudes. Alternatively, these drivers might indeed be bad drivers, as selfreported. In that sense, they might be able to identify safe driving situations very well (thus the significant pro-safety attitude), but may not have the proper skills to judge what a risky driving situation is (thus the non-significant anti-risk attitude). In any case, more research 
is needed to uncover the precise cognitive mechanisms that are at work.

\subsection{Strengths and limitations}

The present study is one of the first to assess implicit attitudes in a traffic psychology context, and is the first study assessing implicit driving attitudes with the GNAT. As a strength of the present work, the use of the research instrument GNAT (rather than Implicit Association Tests as in previous research) readily allowed us to investigate the cognitive structure of implicit attitudes towards safety and risk in depth. In fact, the results then suggest that implicit attitudes towards safe driving and risky driving, respectively, may be separable constructs and might stem from different cognitive processes. Thus, rather than looking at safety and risk as a continuum, it seems that implicit attitudes towards safety and implicit attitudes towards risk are separate dimensions that may vary independently. The results thus indicate the need to measure implicit attitudes towards risky and safe driving separately in future research, too.

However, several limitations should be addressed in future work. The first limitation is the small sample. The sample size is in line with other GNAT studies (e.g., Buhlmann et al., 2011; Knowles \& Townsend, 2012; Nosek \& Banaji, 2001; Teachman, 2007). Nevertheless, these studies applied the GNAT in other psychological research fields. In order to test the robustness of the present results within the field of traffic psychology, further studies with larger samples are necessary. A study with a larger sample size could potentially improve the marginally significant relationships in the present results, as well as detect a relationship between implicit attitudes and self-reported driving behavior among women.

Future studies would also benefit from including other psychologically relevant variables (e.g. explicit attitudes, self-schemas and gender role identification, self-reported driving habits, or objective measures of driving behavior on the road or in a driving simulator), as this may increase the understanding of the relationship between implicit attitudes towards risky and safe driving and driving behavior and skills. Nevertheless, our study illustrates the heuristic, theory-building value of measuring implicit attitudes with instruments such as the GNAT.

\subsection{Summary and implications}

The present study's aims were firstly, to test whether the GNAT is a reliable measure of implicit attitudes towards risky and safe driving; second, whether implicit 
attitudes towards risky driving vs. towards safe driving are separable constructs; and thirdly, to compare drivers' implicit attitudes towards risky and safe driving with their self-reported driving behavior and skill.

The results indicate that implicit attitudes can be measured reliably with the GNAT. They further suggest that implicit pro-safety and anti-risk attitudes may be two separable constructs, rather than opposite endpoints of a single implicit-attitude dimension. Pending replication in future research with larger samples, this observation may contribute to a greater theoretical understanding of the cognitive processes behind safe and risky driving behavior. The difference in implicit attitudes towards safety and risk implies that one should treat the two separately in intervention work: Promoting safety might not deal with the problem of risky driving, and vice-versa. Thus, intervention programs that promote safe driving and combat risky driving separately could be particularly fruitful.

Implicit attitudes and self-reported driving behavior and skills were related significantly among male drivers, but not among female drivers. This result was not explicitly predicted, but is in line with prior research on gender differences in traffic psychology. Above we have speculatively outlined mechanisms whereby symbolic and affective motives, and stereotypical gender-roles (together with other self-schemas) may translate into gender-specific driving behaviors, gender-specific patterns of implicit attitudes, and ultimately, to gender-specific differences in the strength of the implicit attitude-behavior link. These mechanisms should be explored with larger sample sizes in future studies, as they could be important in developing more focused interventions for female or male drivers.

Self-report measures of attitudes and beliefs have not always shown to be predictive of actual behavior (af Wåhlberg, Dorn, De Winter, Dodou \& Freeman, 2012). To know drivers' implicit attitudes towards risky and safe driving, as well as other thoughts and beliefs that they hold implicitly, might give valuable information that can help explain their actual traffic behavior to a greater extent. Consequently, we propose that research on driving behavior may benefit from routinely including measures of implicit thought.

\section{Acknowledgement}

Financial support from by the Danish Council for Strategic Research (Det Strategiske Forskningsråd) is greatly appreciated. We are grateful to the Transport Educational Center (TUC, Fyn) for lending us the pictures applied in the GNAT. 


\section{References}

Aarts, H., Verplanken, B., \& van Knippenberg, A. (1997). Habit and information use in travel mode choices. Acta Psychologica, 96, 1-14.

af Wåhlberg, A.E., Dorn, L., De Winter, J.C.F., Dodou, D., \& Freeman, J.E. (2012).

Commentaries and Responses to "The Driver Behaviour Questionnaire as a predictor of accidents: A meta-analysis". Commentaries lead by Anders af Wåhlberg; Responses lead by J.C.F. de Winter. The following discussion is in response to a 2010 article published in the Journal of Safety Research by J.C.F. de Winter and D. Dodou entitled “The Driver Behaviour Questionnaire as a predictor of accidents: A meta-analysis” (Volume 41, Number 6, pp. 463-470, available on sciencedirect.com). The editors are pleased to provide a forum for this exchange and welcome further comments. Journal of Safety Research, 43, 83-99.

Armitage, C.J., Norman, P., \& Conner, M. (2002). Can the theory of planned behavior mediate the effects of age, gender and multidimensional health locus of control? British Journal of Health Psychology 7, 299-316.

Baron, A.S., \& Banaji, M.R. (2006). The development of implicit attitudes: Evidence of race evaluations from ages 6 and 10 and adulthood. Psychological Science, 17, 53-58. Buhlmann, U., Teachman, B.A., \& Kathmann, N. (2011). Evaluating implicit attractiveness beliefs in body dysmorphic disorder using the Go/No-go Association Task. Journal of Behavior Therapy \& Experimental Psychiatry, 42, 192-197.

Brendl, C.M., Markman, A.B., \& Messner, C. (2001). How do indirect measures of evaluation work? Evaluating the inference of prejudice in the Implicit Association Test. Journal of Personality \& Social Psychology, 81, 760-773

Chan, D.C.N., Wu, A.M.A., \& Hung, E.P.W. (2010). Invulnerability and the intention to drink and drive: an application of the theory of planned behaviour. Accident Analysis \& Prevention, 42, 1549-1555.

Chen, M., \& Bargh, J. A. (1999). Consequences of automatic evaluation: immediate behavioral predispositions to approach or avoid the stimulus. Personality \& Social Psychology Bulletin, 25, 215-224.

DeJoy, D. M. (1989). The optimism bias and traffic accident risk perception. Accident Analysis \& Prevention, 21, 333-340.

Delhomme, P., Grenier, K., \& Kreel, V. (2008). Replication and extension: The effect of the commitment to comply with speed limits in rehabilitation training courses for traffic 
regulation offenders in France. Transportation Research Part F, 11, 192-206.

de Winter, J.C.F., \& Dodou, D. (2010). The driver behaviour questionnaire as a predictor of accidents: a meta-analysis. Journal of Safety Research 41, 463-470.

Dovidio, J.F., Kawakami, K., Johnson, C., Johnson, B., \& Howard, A. (1997). On the nature of prejudice: automatic and controlled processes. Journal of Experimental Social Psychology, 33, 510-554.

Dunham, Y., Baron, A. S., \& Banaji, M. R. (2004). From American city to Japanese Village: A cross-cultural investigation of implicit race attitudes. Child Development, 77, 1268-1281.

Elander, J., West, R., \& French, D. (1993). Behavioral correlates of individual differences in road traffic crash risk: an examination of methods and findings. Psychological Bulletin, 113, 279-294.

Ellaway, A., Macintyre, S., Hiscock, R., \& Kearns, A. (2003). In the driving seat:

psychosocial benefits from private motor vehicle transport compared to public transport. Transportation Research Part F, 6, 217-231.

Evans, L. (1991). Traffic safety and the driver. New York: Van Nostrand Reinhold.

Fazio, R.H., \& Olson, M.A. (2003). Implicit measures in social cognition research: Their meaning and use. Annual Review of Psychology, 54, 297-327.

Glendon, A.I. (2007). Driving violations observed: An Australian study. Ergonomics, 50, 1159-1182.

Greenwald, A.G. \& Banaji, M.R. (1995). Implicit social cognition: Attitudes, self-esteem, and stereotypes. Psychological Review, 102, 4-27.

Greenwald, A.G., McGhee, D.E., \& Schwartz, J.L.K. (1998). Measuring individual differences in implicit cognition: the implicit association test. Personality \& Social Psychology, 74, 1464-1480.

Harré, N., Field, J., \& Kirkwood, B. (1996). Gender differences and areas of common concern in the driving behaviours and attitudes of adolescents. Journal of Safety Research, 27, 163-173.

Harré, N., Foster, S., \& O’Neill, M. (2005). Self enhancement, crash-risk optimism and the impact of safety advertisements on young drivers. British Journal of Social Psychology, 96, 215-230.

Harré, N., \& Sibley, C.G. (2007). Explicit and implicit self-enhancement biases in drivers and their relationship to driving violations and crash-risk optimism. Accident Analysis 
\& Prevention, 39, 1155-1161.

Hatfield, J., Fernandes, R., Faunce, G., \& Job, R.F.S. (2008). An implicit non-self-report measure of attitudes to speeding: Development and validation. Accident Analysis \& Prevention, 40, 616-627.

Iversen, H. (2004). Risk-taking and risky driving behaviour. Transportation Research Part F, 7, 135-150.

Lajunen, T., Corry, A., Summala, H., \& Hartley, L. (1998a). Cross-cultural differences in drivers' self-assessments of their perceptual-motor and safety skills: Australians and Finns. Personality \& Individual Differences, 24, 539-550.

Lajunen, T., Parker, D., \& Stradling, S.G. (1998b). Dimensions of driving anger, agressive and highway code violations and their mediation by safety orientation in UK drivers. Transportation Research Part F, 1, 107-121.

Lajunen, T., \& Summala, H. (1995). Driving experience, personality, and skill and safety motive dimensions in drivers’ self-assessments. Personality \& Individual Differences, 19, 307-318.

Lajunen, T., \& Summala, H. (1997). Effects of driving experience, personality, and driver’s skill and safety orientation on speed regulation and accidents. In T. Rothengatter \& E. Carbonell Vaya (eds.), Traffic and transport psychology: Theory and application (pp. 283-294). Amsterdam: Pergamon.

Lawton, R., Parker, D., Manstead, A., \& Stradling, S.G. (1997). The role of affect in predicting social behaviours: the case of road traffic violations. Journal of Applied Social Psychology, 27, 1258-1276.

Lois, D., \& López-Sáez M. (2009). The relationship between instrumental, symbolic and affective factors as predictors of car use: a structural equation modeling approach. Transportation Research Part A, 43, 790-799.

Knowles, S.E., \& Townsend, E. (2012). Implicit and explicit attitudes toward self-harm: support for a functional model. Journal of Behavior Therapy \& Experimental Psychiatry, 43, 730-736.

Krahé, B., \& Fenske, I. (2002). Predicting aggressive driving behaviour: The role of macho personality, age and the power of the car. Aggressive Behaviour, 28, 21-29.

Kraus, S.J. (1995). Attitudes and the prediction of behavior: A meta-analysis of the empirical literature. Personality \& Social Psychology Bulletin, 21, 58-75.

Maison, D., Greenwald, A.G., \& Bruin, R. (2001). The implicit association test as a measure of implicit costumer attitudes. Polish Psychological Bulletin, 32, 61-69. 
Marcil, I., Bergeron, J., \& Audet, T. (2001). Motivational factors underlying the intention to drink and drive in young male drivers. Journal of Safety Research 32 (4), 363-376.

Martinussen, L.M., Hakamies-Blomqvist, L., Møller, M., Özkan, T., \& Lajunen, T. (2013). Age, gender, mileage and the DBQ: The validity of the driver behavior questionnaire in different driver groups. Accident Analysis \& Prevention, 52, 228-236.

Martinussen, L.M., Møller, M., \& Prato, G.P. (2014). Assessing the relationship between the Driver Behavior Questionnaire and the Driver Skill Inventory: Revealing sub-groups of drivers. Transportation Research Part F, 26, 82-91.

Näätänen, R., \& Summala, H. (1976). Road-user behavior and traffic accidents. Amsterdam and New York: North/Holland/American Elsevier.

Nosek, B.A., \& Banaji, M.R. (2001). The go/no-go association task. Social Cognition, 19, 625-664.

Nosek, B.A., Greenwald, A.G., \& Banaji, M.R. (2007). The implicit association test at age7: A methodological and conceptual review (pp 265-292). In J. A. Bargh (Ed.), Automatic processes in social thinking and behavior. Psychology Press.

Özkan, T., \& Lajunen, T. (2005). Why are there sex differences in risky driving? The relationship between sex and gender-role on aggressive driving, traffic offences, and accident involvement among young Turkish drivers. Aggressive Behavior, 31, 547-558.

Özkan, T., \& Lajunen, T. (2006). What causes the difference in driving between young men and women? The effects of gender roles and sex on young drivers' behaviour and selfassessment of skills. Transportation Research Part F, 9, 269-277.

Parker, D., Lajunen, T., \& Stradling, S.G. (1998). Attitudinal predictors of interpersonally aggressive violations on the road. Transportation Research Part F, 1, 11-24.

Parker, D., Manstead, A.S.R., \& Stradling, S.G. (1992a). Determinants of intention to commit driving violations. Accident Analysis \& Prevention, 24, 117-131.

Parker, D., Manstead, A.S.R., Stradling, S.G., Reason, T.J., \& Baxter, J.S. (1992b). Intention to commit driving violations: an application of the theory of planned behavior. Journal of Applied Psychology 77, 94-101.

Parker, D., Reason, J., Manstead, A., \& Stradling, S.G. (1995a). Driving errors, driving violations and accident involvement. Ergonomics, 38, 1036-1048.

Parker, D., West, R., Stradling, S.G., \& Manstead, A. (1995b). Behavioral characteristics and involvement in different types of traffic accidents. Accident Analysis \& Prevention, 27, 571-581. 
Perugini, M. (2005). Predictive models of implicit and explicit attitudes. British Journal of Social Psychology, 44, 29-45.

Phelps, E.A., O’Connor, K.J., Cunningham, W.A., Funayama, E.S., Gatenby, J.C., Gore, J.C., \& Banaji, M.R. (2000). Performance on indirect measures of race evaluation predicts amygdala activation. Journal of Cognitive Neuroscience, 12, 729-738.

Reason, J.T., Manstead, A., Stradling, S.G., Baxter, J., \& Campbell, K. (1990). Errors and violations on the road - a real distinction. Ergonomic, 33, 1315-1332.

Rimmö, P-A., \& Åberg, L. (1999). On the distinction between violations and errors: sensation seeking associations. Transportation Research Part F, 2, 151-166.

Rydell, R.J., \& McConnell A.R. (2006). Understanding implicit and explicit change: a system of reasoning analysis. Journal of Personality \& Social Psychology, 91, 995-1008.

Siebler, F., González, R., Ordóñez, G., Bohner, G., Haye, A., Sirlopú, D., Millar, A., De Tezanos-Pinto, P., \& Torres, D. (2010). The Category-Focus Implicit Association Test. Social Psychology, 41, 105-110.

Sibley, C.G. \& Harré, N. (2009a). The impact of different styles of traffic safety advertisements on young drivers' explicit and implicit self-enhancement biases. Transportation Research Part F, 12, 159-167.

Sibley, C.G. \& Harré, N. (2009b). A gender role socialization model of explicit and implicit biases in driving self-enhancement. Transportation Research Part F, 12, 452-462.

Steg, L. (2005). Car use: lust and must. Instrumental, symbolic and affective motives for car use. Transportation Research Part A, 39, 147-162.

Sümer, N., Özkan, T., \& Lajunen, T. (2006). Asymmetric relationship between driving and safety skills. Accident Analysis \& Prevention, 38, 703-711.

Swanson, J.E., Rudman, L. A., \& Greenwald, A.G (2001). Using the implicit association test to investigate attitude-behavior consistency for stigmatized behavior. Cognition \& Emotion, 15, 207-230.

Teachman, B.A. (2007). Evaluating implicit spider fear associations using the Go/No-go Association Task. Journal of Behavior Therapy, 38, 156-167.

Teachman, B.A., Gapinski, K.D., Brownell, K.D., Rawlins, M., \& Jeyaram, S. (2003).

Demonstration of implicit anti-fat bias: The impact of providing causal information and evoking empathy. Health Psychology, 22, 68-78.

Teachman, B.A., Gregg, A.P., \& Woody, R.S. (2001). Implicit association for fear-relevant 
stimuli among individuals with snake and spider fears. Journal of Abnormal Psychology, 110, 226-235.

Ulleberg, P. \& Rundmo, T. (2003). Personality, attitudes and risk perception as predictors of risky driving behaviour among young drivers. Safety Science, 41, 427-443.

Verplanken, B., Aarts, H.,van Knippenberg, A., \& Moonen, A. (1998). Habit versus planned behaviour: a field experiment. British Journal of Social Psychology, 37, 111-128.

Verplanken, B., Aarts, H., van Knippenberg, A., \& van Knippenberg, C. (1994). Attitude versus general habit: Antecedents of travel mode choice. Journal of Applied Social Psychology, 24, 285-300.

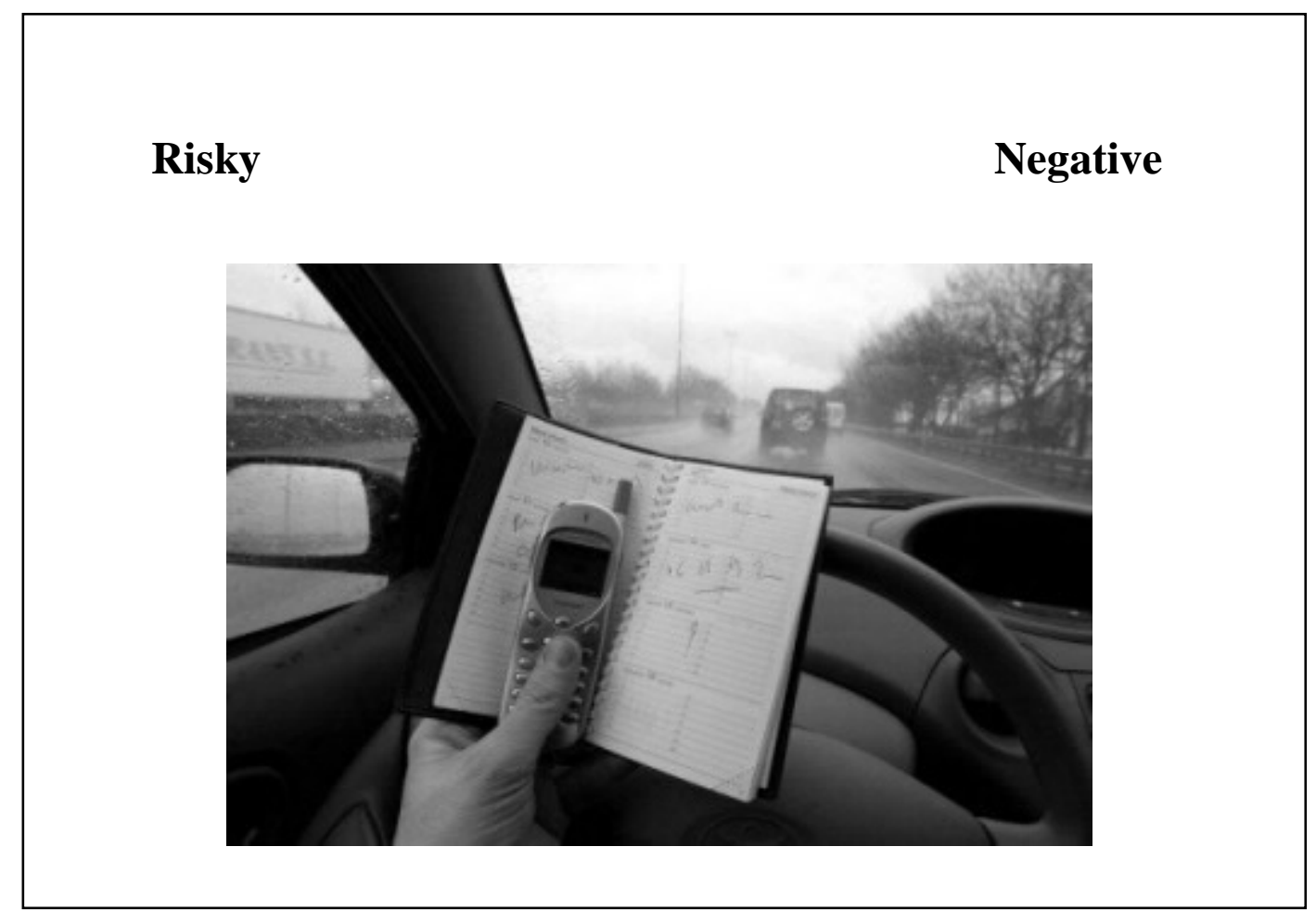

Fig.1. The GNAT procedure as seen by the participants on a typical classification trial. Target category and attribute dimension are presented right and left at the top of the computer screen. Participants press space bar (the "go" response) if the stimulus on the screen belongs to either the target category or the attribute dimension; otherwise they do nothing (the "no-go" response). Copyright of the pictures: Dansk Kørelærer Union. 
Table 1

Sample characteristics

\begin{tabular}{lcc}
\hline & Males & Females \\
\hline$N$ & 22 & 31 \\
Age (in years), mean & 44.4 & 50.9 \\
Age, standard deviation & 16.9 & 15.5 \\
\hline
\end{tabular}

Table 2

Correlations between implicit attitudes towards risky and safe driving

\begin{tabular}{lccc}
\hline & Safe600 & Risk750 & Risk600 \\
\hline Safe750 & $.40^{* *}$ & $.27^{+}$ & $.30^{*}$ \\
Safe600 & & .18 & $.27^{+}$ \\
Risk750 & & & $.45^{* *}$ \\
\hline
\end{tabular}

Note. Cell entries are Pearson correlation coefficients. ${ }^{* *} p<.01,{ }^{*} p<.05,{ }^{+} \mathrm{p}<.10$. Due to listwise deletion of cases with partly missing data, all $N=49$.

\section{Table 3}

Means and standard deviations of the implicit attitudes scores, and their correlations with the DBQ and DSI scores.

\begin{tabular}{|c|c|c|c|c|c|}
\hline & & Mean & $S D$ & $D S I$ & $D B Q$ \\
\hline \multirow[t]{2}{*}{$\begin{array}{l}\text { Whole } \\
\text { sample }\end{array}$} & Implicit attitude risk & .82 & .88 & .07 & $.23^{+}$ \\
\hline & Implicit attitude safety & .70 & .89 & -0.17 & .11 \\
\hline \multirow[t]{2}{*}{ Male } & Implicit attitude risk & .76 & .97 & -.09 & $.44^{*}$ \\
\hline & Implicit attitude safety & .75 & .76 & $-.63^{* *}$ & .07 \\
\hline \multirow[t]{2}{*}{ Female } & Implicit attitude risk & .87 & .67 & .19 & .04 \\
\hline & Implicit attitude safety & .82 & .99 & .08 & .13 \\
\hline
\end{tabular}

